\title{
CARACTERÍSTICAS ERGONÔMICAS DOS MATERIAIS DE CALCADOS FEMININOS PARA A TOMADA DE DECISÃO E COMPORTAMENTO DAS UŚUÁRIAS
}

Jefferson Sobral Santos

Isis Tatiane de Barros Macêdo Veloso

\begin{abstract}
Resumo: Objetivando entender as preferências de materiais em calçados femininos do Atelier Rivaldo Soares, a partir de um nicho de consumidoras na cidade de Caruaru-PE, utilizando a quinta etapa do Modelo de Avaliação dos Materiais: Permatus - Percepção dos Materiais Pelos Usuários (Dias, 2009), o estudo realizou uma análise conativa em grupo focal com seis participantes. Como resultado da avaliação e análise, foi compreendido os aspectos ergonômicos dos materiais como propulsores de uma tomada de decisão na compra do produto e no comportamento da usuária para com a usabilidade do calçado. Nesse ínterim, a pesquisa se torna uma fonte de informações objetivas para o desenvolvimento de produtos, a partir de requisitos propostos pela própria usuária.
\end{abstract}

Palavras-chave: ergodesign, materiais, design emocional

\section{INTRODUC̣ÃO}

No início dos tempos, após o contato do homem com os materiais, estes exerceram fortes influências na configuração de períodos vigentes na sociedade e em questões relacionadas a novas soluções, em detrimento a uma evolução social e tecnológica. Manzini (1993), afirma ser o material um dos elementos mais importantes na configuração de um produto.

Os designers são responsáveis desde a seleção de materiais até a finalização do produto, por criar uma mensagem, a partir da utilização de uma matéria-prima e suas características. Os usuários, enquanto receptores dessa mensagem, compreendem os produtos perante diversos fatores que os circundam, como cultura e preferências. $\mathrm{Na}$ perspectiva dos usuários, de acordo com Sanders (2002), apud. Santa Rosa (2013), podemos acessar as experiências das pessoas e usar como fonte de inspiração e ideias para o projeto em questão.

Doordan (2003, p. 38) afirma que, “a seleção de materiais influencia significativamente a forma, a função e a percepção de um produto". O autor salienta, ainda, que novos materiais suscitam novos problemas.

Isso posto, o estudo analisa os materiais de calçados femininos no nível emocional conativo (que está relacionado à questão motivacional do material no processo de decisão, como escolha, uso, compra, adesão, etc) sendo utilizado e referenciado na pesquisa a partir da quinta etapa do Permatus (Percepção dos Materiais Pelos Usuários) como modelo de avaliação dos materiais pelos usuários, desenvolvido por DIAS (2009). 
A partir de uma amostragem realizada com seis consumidoras de calçados femininos do Atelier Rivaldo Soares na cidade de Caruaru-PE, como resultados, a pesquisa apresentou os principais fatores dos materiais relacionados à ergonomia, diretamente ligados a uma tomada de decisão na escolha do produto e a questões de usabilidade, elencados e justificados a partir da opinião das usuárias.

A pesquisa denota a importância da interdisciplinaridade, pois, assim como o ergodesign, a área de materiais se torna uma ponte que agrupa questões e necessidades a serem solucionadas para o bem-estar de um grupo ou da sociedade, em geral, através de uma interface.

\section{FUNDAMENTOS TEÓRICOS}

\subsection{Seleção de Materiais}

Sendo um processo determinante sobre várias situações que podem ocorrer após a finalização e comercialização do produto, como por exemplo, sua aceitação ou rejeição pelos consumidores, a seleção de materiais é vista como o elo entre ideia e a materialização de um objeto, podendo ser usada, perante diferentes circunstâncias, que devem ser brevemente analisadas e levadas em conta durante essa fase (FERRANTE, 2010, P. 158). Ashby (2011, p. 123) "design envolve escolha, e uma escolha é feita a partir de uma enorme gama de ideias e dados - entre eles, a escolha de materiais e processos".

Dias (2009, p. 36), salienta que, o processo de seleção de materiais ocorre em diferentes situações:

- Na criação de um novo produto não havendo nenhuma limitação sobre o material;

- Na criação de um novo produto para uma empresa que já tenha um processo produtivo que pré-determina uma classe de materiais;

- Modificações de um produto, ou o seu redesign em função da necessidade de um melhor desempenho técnico;

- A alteração do material para a redução de custos;

- Trabalhar sempre com materiais disponíveis e com custos reduzidos.

Vê-se, portanto, que os materiais possuem grande importância frente aos Processo de Desenvolvimento de Produtos (PDP), tornando-se fator chave para o sucesso ou fracasso de um produto, além de estarem ligados a diferentes interesses, que por sua vez, podem atribuir valor à matéria-prima, a partir de seu grau de conhecimento.

\subsection{A comunicação através dos materiais}

No que diz respeito aos materiais, em consonância com Manzini (2005, p. 147), "0 designer tem um papel relevante na escolha e aplicação dos materiais empregados em produtos de produção em série, mesmo sabendo que não vai estar envolvido com a origem ou com o fim destes materiais ao acessar o clico de vida dos produtos".

De acordo com Doordan (2003), o designer deve estar atento ao que diz respeito a novas tecnologias. Essa abordagem revela que novos materiais possibilitam novas linguagens formais para sua concepção.

Ashby (2011), refere-se a novos materiais com o ponto de vista de que "são o ponto de partida para os designers - eles inspiram e podem ser manipulados para se obter produtos que nunca tinham parecido possíveis antes... com frequência o desafio nesse 
setor industrial é lembrar o elemento humano e não focar apenas a tecnologia".

Em detrimento aos fatos, surge uma nova abordagem referente aos materiais. Doordan (2003), propõe um novo modelo quanto aos conhecimentos dos materiais, que se baseia na tríade: Fabricação, Aplicação e Apreciação (Figura 1):

Figura 1: Domínios de conhecimento dos materiais. Fonte: Adaptado de Doordan (2003).

1

Fabricação:

preparação da matéria-prima

\section{2}

Aplicação: design linguagem

\section{2}

Essa nova abordagem proposta pelo autor, conota um posicionamento peculiar, onde o designer está presente nas duas últimas fases apresentadas, corroborando com a ideia de Manzini (1993) apud Dias (2009, p. 2), ao afirmar que designer é "responsável pela criação da relação entre sujeito e matéria".

\subsection{Sensação e Percepção}

Experiência do usuário, funções, percepção e significados, são termos bastante utilizados entre pesquisadores na atualidade, especialmente entre áreas criativas como o Design, por exemplo. As quatro abordagens especificadas acima, são fenômenos ligados à emoção, que por sua vez, está configurada nesta seção, em outras duas áreas: sensação e percepção. Atinente a isto, a emoção hodiernamente poderia ainda ser uma área pouco abordada, no sentido exploratório da psicologia humana. Isso quer dizer que, em sua maioria, as pesquisas tinham em seu cerne, questões relacionadas às emoções negativas como estresse, medo, ansiedade e raiva, (NORMAN, 2008 P. 38).

No vocabulário da Ergonomia, emoção, prazer, afeto e satisfação eram termos quase inexistentes, até pouco tempo. Cada vez mais, estudos vêm sendo desenvolvidos envolvendo a questão da satisfação de uso, relacionadas às sensações e percepções dos usuários. Deste modo, passou a surgir na área o termo "hedonomia" que, além da usabilidade, "abrangeria, também, questões focadas na promoção da experiência prazerosa e na individualização e customização dos sistemas" (MONT'ALVÃO E DAMAZIO, 2008). Moraes (2002) apud Mont'alvão (2008) complementa que, no ergodesign, é preciso também considerar os aspectos emocionais envolvidos, pois a "agradabilidade" não é apenas uma propriedade do produto, mas consequência de sua interação com o usuário.

Em se tratando de analisar a relação produtos-materiais, a experiência do usuário pode estar condicionada a um processo percebido de forma dificultosa, muito relacionada apenas à interpretação das características dos materiais. Cardoso (2013) aborda o produto quanto a suas funções, e exemplifica a seguinte indagação: "Que os objetos possuem significados é claro para todos. Como eles significam, exatamente, já é um pouco mais melindroso".

Quanto as características dos produtos em diferencial competitivo e vantajoso, as emoções têm se tornado fortes meios para a tomada de decisão na compra de um produto (DESMET, 2005).

\section{METODOLOGIA}

Os procedimentos metodológicos/avaliativos foram realizados a partir da quinta etapa 
do modelo Permatus (DIAS, 2009). O Modelo foi escolhido devido seu caráter inovador e sua fácil aplicação, se adequando a necessidade do estudo no que diz respeito a região, local e segmento pretendido.

No experimento, foi utilizada uma técnica mista de pesquisa: aplicação de questionário individual e Grupo Focal, onde participaram 6 usuárias-alvo, acompanhadas por dois líderes e seis auxiliares. O experimento foi realizado no Bloco Administrativo do Centro Acadêmico do Agreste da UFPE em Caruaru, obedecendo aos seguintes requisitos:

- Espaço adequado para a apresentação de seis calçados em uma mesa, de modo a oferecer espaço para movimentação durante a interação (uso) dos produtos; dispor de área para apresentação de qualquer material impresso necessário ao teste.

- Possibilitar concentração, ou seja, sem ruídos visuais ou sonoros.

Figura 2: Ambiente do experimento / Calçados selecionados para avaliação. Fonte: Dados da pesquisa.

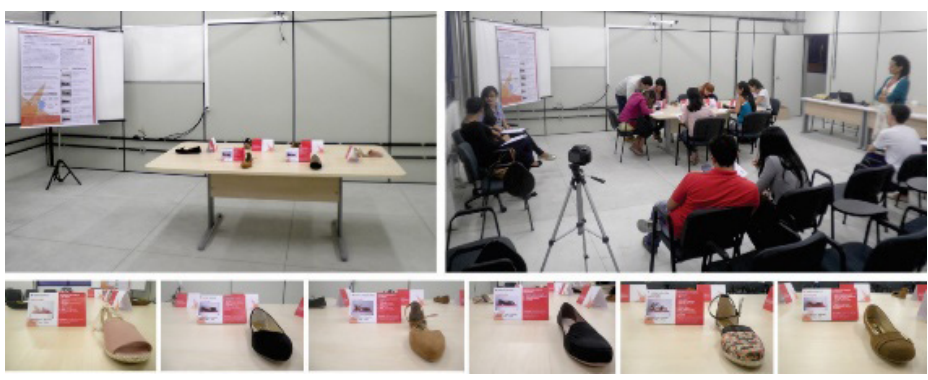

O tratamento e análise dos dados foi realizado com recursos qualitativos (observação, vídeo, fotografia, áudio, questionário e grupo focal) e quantitativos (dados referentes a questões respondidas por escala). O software Excel 2016 foi utilizado para geração de gráficos, tabelas e figuras, auxiliando a interpretação dos dados e favorecendo a eficácia dos resultados.

\section{RESULTADOS}

Tendo em vista se tratar da análise conativa, o objetivo foi entender as motivações e preferências das participantes com relação aos materiais e produtos a partir de características ergonômicas.

Durante a análise conativa, foi avaliado o perfil semântico dos materiais. As informações abaixo, correspondem ao calçado avaliado e os atributos de cunho ergonômico dados pela consumidora ao material de que ele é confeccionado:

Figura 3: Calçados em análise.

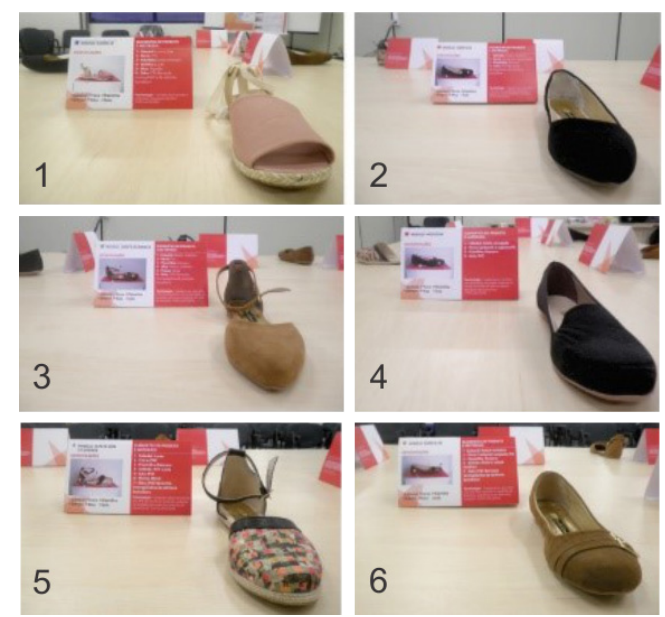


- Calçado 1 (materiais: lona e juta): leve;

- Calçado 2 (material: nobuck): leve e seguro;

- Calçado 3 (material: nobuck): textura suave e leve;

- Calçado 4 (material: cetim corrugado): leve e seguro;

- Calçado 5 (material: lurex): resistente, bem acabado, leve e seguro;

- Calçado 6 (material: nobuck): resistente, leve, macio e seguro.

As usuárias puderam analisar com eficácia a usabilidade dos produtos, percebendo como se comportam os elementos e o calçado como um todo, passando a expressar suas percepções imediatas, como mostra a figura 4:

Figura 4: Avaliação dos calçados: (a) sorriso; (b) usabilidade; (c) observação geral. Fonte: Dados da pesquisa.

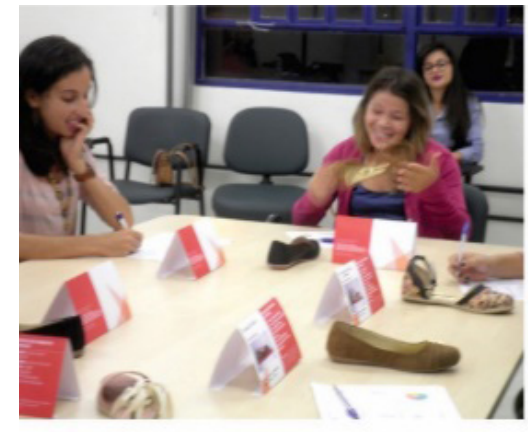

(a)

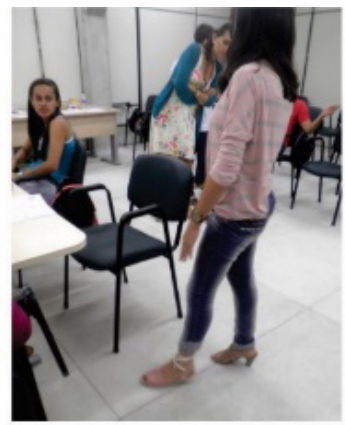

(b)

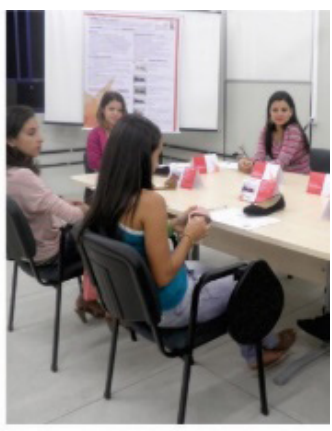

(c)

Foi percebido que o atributo "leve" está presente na análise das usuárias em todos os materiais avaliados. O material nobuck, por exemplo, tendo sido aplicado em três diferentes calçados dos seis que foram expostos, foi avaliado com atributos ergonômicos parecidos. Em algumas análises, outros atributos (seguro, resistente) foram acrescidos ao calçado, podendo ser relacionado ao formato ou experiência prévia da usuária com o modelo.

Assim, foram elencadas algumas importantes considerações:

- Todos os calçados receberam o atributo "leve". Tendo em vista os diferentes materiais apresentados, esta pode ser uma característica positiva (do ponto de vista ergonômico, podendo ser traduzida como limpeza visual, leveza no calçar, por exemplo).

- Três (50\%) calçados (2, 4 e 5), foram avaliados como "seguro".

- Três (50\%) calçados (2,4 e 6) foram avaliados como “comum”. Esse é um aspecto negativo da avaliação, que pode estar relacionado não somente ao material, mas a outros fatores que impactam no projeto do calçado e consequentemente não agradam as usuárias no uso, por exemplo.

A análise semântica demostrou importantes considerações acerca de como é expresso o conhecimento pelas usuárias em relação a um determinado material, a partir de diversas formas de interação: visual, tátil, háptica, entre outras. Ressaltase que, em geral, as usuárias fizeram atribuições que relacionam o material à função prática do produto, assim como tomam decisões a partir de aspectos estéticos, simbólicos, culturais, além da experiência que tiveram com o material avaliado, onde descreveram situações atreladas a fatores ergonômicos, e portanto, agem diretamente no comportamento e tomada de decisão.

Por conseguinte, o estudo buscou entender as preferências das participantes com 
relação aos materiais e produtos expostos. Para isso, foi pedido que escolhessem dois dos seis calçados em análise, que elas gostariam e comprariam, explicando o porquê da escolha. Assim como escolhessem os dois que menos gostaram e não comprariam, descrevendo também o motivo. Após, foi pedido para que descrevessem os itens e detalhes positivos identificados nos calçados e qual seria o calçado/material ideal.

Figura 5: Preferência: calçados que a usuária mais gostou e compraria. Fonte: Dados da pesquisa.

Preferências: calçados que as usuárias mais gostaram

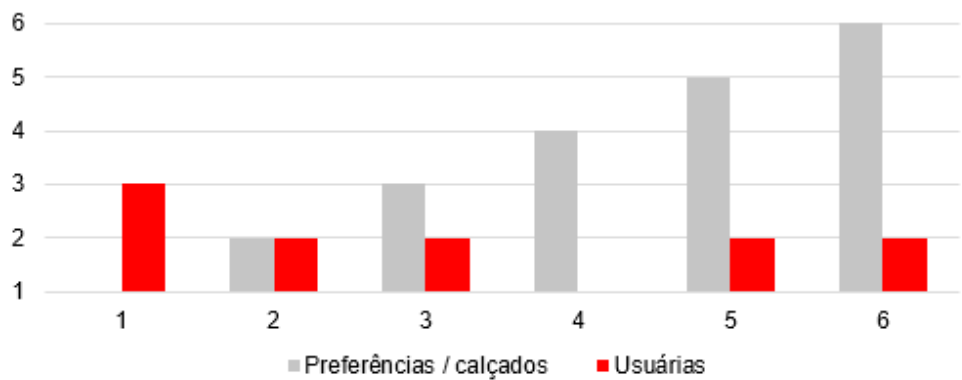

Com base na Figura 5, surgiram as seguintes considerações, baseadas nas opiniões positivas das usuárias:

- Calçados 1 e 3: Beleza e conforto;

- Calçados 2 e 6: Conforto e parece com minha personalidade;

- Calçados 3 e 6: Bonitos e chama atenção;

- Calçados 2 e 5: Simples e sofisticado / Diferente e confortável;

- Calçados 1 e 5: Diferentes e confortáveis;

- Calçados 1 e 4: Diferenciados, elementos harmoniosos e materiais diferentes.

Figura 6: Preferência: calçados que a usuária menos gostou e não compraria. Fonte: Dados da pesquisa.

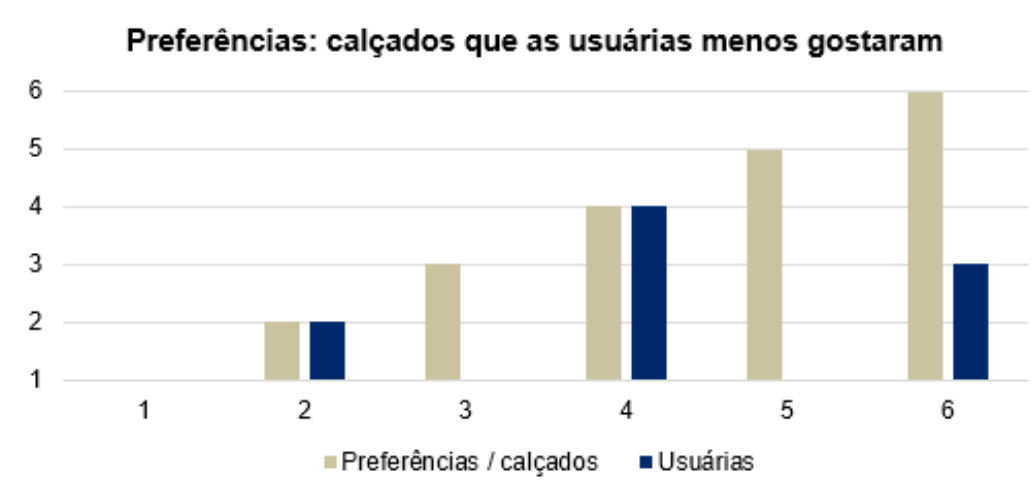

As opiniões negativas das usuárias quanto aos calçados, atreladas a tomada de decisão e compra, apontaram, conforme exposto na figura 7, o seguinte:

- Calçados 6 e 2: Normal, não combinam comigo e acabamento ruim;

- Calçados 1 e 4: Não são confortáveis, apesar do 1 ter design atraente;

- Calçados 5 e 4: Feios e mal acabados;

- Calçados 4 e 6: Sola dura e acabamento ruim / Simples e sem graça;

- Calçados 2 e 4: Feio e desconfortável / Sem graça e mal acabado; 
- Calçados 3 e 6: Forma e acabamentos ruins.

No calçado 1, três usuárias (50\%) afirmaram gostar e comprariam. Em relação aos que menos gostaram e não comprariam, o calçado 4 foi o de maior representatividade, apontado por quatro usuárias (66,7\%).

O estudo buscou, também, entender qual seria o calçado/material ideal na opinião das usuárias, onde elas puderam descrever sua resposta em texto corrido. Portanto, os resultados foram agrupados e apresentados conforme a ordem de cada usuária:

- Couro, com sola confortável e resistente;

- Algum material com conforto, segurança, bom acabamento e beleza;

- Que seja bonito e confortável;

- Com elementos suaves, com palmilha confortável e o mínimo de salto para que o pé fique plano;

- Com acabamento perfeito, design diferenciado mas que proporcione conforto.

- Ergonômico, elementos visuais interessantes e diferenciados e de boa usabilidade.

É notório que o ponto chave dentre as respostas foi o "conforto". Esta característica, por sua vez, pode estar ligada ao bom acabamento, resistência, segurança e ergonomia, de modo geral, que foram também aspectos citados pelas participantes. Assim como design diferenciado, por estar diretamente ligado aos aspectos: beleza, bonito, elementos suaves, interessantes e diferenciados.

\section{CONCLUSÃO}

Foi verificado que na cidade de Caruaru-PE, a indústria calçadista ainda é pequena, mas já possui representatividade a partir de pequenas empresas que confeccionam e vendem o próprio produto, como é o caso do Atelier Rivaldo Soares.

O Permatus é um modelo de avaliação dos materiais pelos usuários bastante eficaz. Sendo maleável a depender do estudo, o pesquisador consegue adaptar suas ferramentas e técnicas, como é o caso desta pesquisa, onde foi utilizada apenas uma etapa das seis que competem ao Modelo. São possibilidades oferecidas ao pesquisador que conotam em uma perspectiva não habitual de estudo e contato com a indústria, assim como, com o usuário, elucidando correntes problemas com maior eficácia.

Com o cumprimento dos objetivos do estudo, a interpretação dos atributos subjetivos dos materiais de calçados femininos explorados no experimento, anotações e registros fotográficos, são materiais de grande relevância para um eficaz projeto de produto, ou um redesign de calçados, quando se trata do Atelier em estudo, que já possui suas coleções e cartela de produtos.

Como resultado da fase conativa da percepção das usuárias para com os atributos diversos dos calçados, entre eles os ergonômicos, verificou-se que os materiais preferidos são os que além de se destacar em aspectos de inovação e estéticos como cor e forma, devem apresentar características que refletem diretamente no conforto do calçado, proporcionando bem estar.

Portanto, conclui-se que diversos fatores levam a usuária a tomar uma decisão de compra sobre um produto. Mas, nesse momento, prevalece aquele que a encanta em sua função prática, e no seu desenrolar, que vai desde o calçar, andar e sentir. 
Entende-se que Ergodesign enquanto campo de atuação, pode contribuir de forma direta, eficaz, respeitando ainda as necessidades da indústria e usuários enquanto atores que se envolvem no processo de fabricação de artefatos que voltarão para suas casas. Diz respeito a construção de produtos que estão presentes em nosso dia-a-dia, como os calçados que são essenciais na conjuntura atual da sociedade.

\section{REFERÊNCIAS}

ASHBY, Michael. F. Materiais e design: arte e ciência da seleção de materiais no design de produto/Michael Ashby e Kara Johnson; tradução de Arlete Simille Marques; revisão técnica de Mara Martha Roberto e Ágata Tinoco. Rio de Janeiro: Elsevier, 2011.

CARDOSO, Rafael. Design para um mundo complexo / Rafael Cardoso. São Paulo: Cosac Naify, 2013.

DESMET, P. M. A. Measuring Emotions: development and application of an instrument to measure emotional responses to products. In: BLYTHE, M. A.; OVERBEEKE, K.; MONK, A. F. (Eds). Funology: from usability to Enjoyment. Dordrecht: Kluwer Academic Publishers, 2005. Cap. 9, p. 111-123.

DIAS, M.R.A.C. Percepção dos materiais pelos usuários: modelo de avaliação Permatus. Tese (doutorado) - Programa de Pós-Graduação em Engenharia do Conhecimento, PPGEGC, UFSC, Florianópolis, 2009.

DOORDAN, Dennis P. On Materials. Design Issues. n. 19, 2003.

FERRANTE, Maurizio. A materialização da ideia: noções de materiais para o design de produto/Maurizio Ferrante, Yuri Walter. Rio de Janeiro: LTC, 2010.

MANZINI, Ezio. A matéria da invenção. Lisboa: Centro Português de Design, 1993.

MANZINI, Ezio. 0 desenvolvimento de produtos sustentáveis / Ezio Manzini, Carlo Vezzoli; tradução de Astrid de Carvalho. 1. Ed. 1. Reimpr. São Paulo: Editora da Universidade de São Paulo, 2005.

MONT'ALVÃO, Claudia. Hedonomia, ergonomia afetiva: afinal, do que estamos falando? In: MONT’ALVÃO, Claudia; DAMAZIO, Vera (org). Design, ergonomia e emoção. Rio de Janeiro: Mauad X: FAPERJ, 2008.

MONT’ALVÃO, Claudia; DAMAZIO, Vera (org). Design, ergonomia e emoção. Rio de Janeiro: Mauad X: FAPERJ, 2008.

NORMAN, Donald A. Design emocional: por que adoramos (ou detestamos) os objetos do dia-a-dia/Donald A. Norman; tradução de Ana Deiró. Rio de Janeiro: Rocco, 2008.

SANTA ROSA, José Guilherme. Ergodesign participativo: um possível caminho para a inovação no Design de interfaces, produtos, ambientes, serviços e processos. Ergonomia design usabilidade interação / Ana Cristina L. S. Barbosa, Márcia Moreira Rangel, Myrtes Raposo, organizadoras. Juiz de Fora: MAMM/UFJF, 2013.

Sobre os autores:

Jefferson Sobral Santos (bacharel), UFPE <jeffersonsobra国hotmail.com>

Isis Tatiane de Barros Macêdo Veloso (doutora), UFCG <isis.veloso@ufcg.edu.br> 